\title{
ENZIMAS EXÓGENAS NA ALIMENTAÇÃO DO PEIXE GUPPY (Poecilia reticulata)
}

(Exogenous enzymes in food fish guppy Poecilia reticulata)

\author{
Veruska Dilyanne Silva Gomes ${ }^{1}$, José Humberto Vilar da Silva, Cácio Ribeiro Cavalcanti, Mário Cesar de \\ Lima, José Jordão Filho, Alda Lúcia de Lima Amâncio \\ ${ }^{1}$ Correspondência: veruska_sgomes@yahoo.com.br
}

RESUMO: O mercado do peixe ornamental exige um animal com tamanho adequado em um período curto de produção, para atender as exigências nutricionais estratégias devem ser implantadas, como a utilização de enzimas exógenas nas rações. A pesquisa foi desenvolvida com o objetivo de avaliar a influencia da suplementação enzimática no desempenho do peixe ornamental guppy. Foram testadas duas dietas, sendo uma suplementada com as enzimas exógenas protease, fitase e alfa-amilase. Foram avaliados: o peso final, ganho de peso, conversão alimentar, comprimento total e padrão, ganho em comprimento total e padrão, altura, largura, taxa de crescimento específico; taxa de desenvolvimento específico e fator de condição de Fulton. A suplementação enzimática influenciou de maneira positiva o crescimento e desenvolvimento dos peixes ornamentais guppys.

Palavras-chave: Aquariofilia, lebiste, piscicultura ornamental

ABSTRACT: The ornamental fish market requires an animal with adequate size in a short period of production, to meet the nutritional requirements strategies should be implemented, such as the use of exogenous enzymes in diets. The research was conducted in order to evaluate the influence of enzyme supplementation on performance ornamental guppy fish. Two diets were tested, one supplemented with exogenous enzymes protease, phytase and alpha amylase. Were evaluated: body weight, weight gain, feed conversion, length complete and standard, gain in total and standard length, height, width , specific growth rate ; Specific development rate and Fulton condition factor. Enzyme supplementation influenced positively the growth and development of guppys ornamental fish.

Key Words: Aquariums, lebiste, ornamental fish 


\section{INTRODUÇÃO}

Para a sustentabilidade da produção de peixes ornamentais, tecnologias devem ser empregadas visando possibilitar menor tempo de cultivo e redução de impactos ambientais causados pela eutrofização da água; fatores diretamente proporcionais à produção de rações com alta digestibilidade, palatabilidade e formas físicas que atendem a necessidade da espécie em todos os seus estágios de vida (Zuanon et al., 2011).

Este sistema de produção deve atender as exigências de mercado, fornecendo um animal com tamanho adequado em um período curto de produção. Para isso, Estratégias como manejo alimentar (SANTOS, et. al., 2014) e inclusão de aditivos, como as enzimas digestivas, nas rações podem ser utilizadas.

O peixe ornamental guppy (Poecilia reticulata) é um animal de pequeno porte; vivíparo; apresenta dimorfismo sexual, sendo as fêmeas mais altas e os machos apresentando corpo alongado, intensa pigmentação, nadadeira caudal com maior comprimento e órgão copulador chamado gonopódio (Munakata e Kobayashi, 2010).

Estes peixes são amplamente produzidos e comercializados no cenário ornamental, no entanto, pesquisas relacionadas a espécie estão concentradas principalmente em ensaios de toxicidade (Boock e Machado Neto, 2005), bioindicadores ambientais (Souza et. al., 2013), produção em água de reuso (Santos et. al., 2015), comportamento reprodutivo (Weinstein e Zimmer, 2015) e no combate as larvas do Aedes aegypti (Cavalcanti et. al., 2007); pesquisas relacionadas a nutrição e alimentação da espécie ainda são escassas. Mediante 0 exposto, 0 trabalho foi desenvolvido com o objetivo de avaliar a influencia da suplementação enzimática no desempenho do peixe ornamental guppy.

\section{MATERIAL E MÉTODOS}

O experimento foi desenvolvido no Laboratório de Aquicultura da Universidade Federal da Paraíba, no município de Bananeiras-PB, por um período de 35 dias.

Foram utilizados 27 alevinos de guppy com peso inicial de $0,0183 \pm 0,0018 \mathrm{~g}$ e comprimento total inicial $0,9 \mathrm{~cm}$; distribuídos em aquários de vidro com capacidade para 2 litros. Sendo, dois tratamentos com três repetições.

Os peixes foram alimentados as 8:00hs, 11:30hs, 14:30hs e 17:00hs, até saciedade aparente dos animais. Todos os dias era realizada a renovação de $60 \%$ da água dos aquários, com retirada de fezes e resíduos por meio de sifonamento; e renovação total da água com lavagem dos aquários semanalmente. As dietas experimentais foram formuladas visando conter $30 \%$ de proteína bruta e $3000 \mathrm{kcal} / \mathrm{kg}$ de energia digestível (tabela 1), na dieta contendo enzimas exógenas foram adicionadas as seguintes enzimas: protease, alfa-amilase e fitase.

\begin{tabular}{|c|c|c|}
\hline Ingredientes (Kg) & Ração Controle & Dieta com enzimas \\
\hline Farelo de soja & 45,520 & 45,520 \\
\hline Mino & 32,940 & 32,940 \\
\hline Farinha de peixes & 10,000 & 10,000 \\
\hline Farelo de trigo & 6,000 & 6,000 \\
\hline Óleo de soja & 3,480 & 3,480 \\
\hline Fosfato bicalcico & 0,930 & 0,930 \\
\hline Sal comum & 0,300 & 0,300 \\
\hline Suplem ento mineral e vitaminico ${ }^{1}$ & 0,500 & 0,500 \\
\hline Vtamina C & 0,006 & 0,006 \\
\hline BHT & 0,020 & 0,020 \\
\hline Inerte & 0,100 & 0,020 \\
\hline Fitase & & 0,020 \\
\hline Alfa-amilase & - & 0,020 \\
\hline Protease & - & 0,040 \\
\hline L-Lisina HCL & 0,094 & 0,094 \\
\hline L-Treonina & 0,040 & 0,040 \\
\hline \multirow{2}{*}{ DL-Metionina } & 0,073 & 0,073 \\
\hline & 100,00 & 100,00 \\
\hline \multicolumn{3}{|l|}{ Composiçăo nutricional (\%) } \\
\hline Matéria seca & 85,640 & 85,640 \\
\hline Proteina Bruta (\%) & 30,000 & 30,000 \\
\hline Energia Bruta (KcalKg) & 3000 & 3000 \\
\hline Fibra bruta $(\%)$ & 3,946 & 3,946 \\
\hline Fósforo total (\%) & 0,955 & 0,955 \\
\hline Cálcio & 1,500 & 1,500 \\
\hline Metionina + cistina total & 0,962 & 0,962 \\
\hline Metionina total & 0,522 & 0,522 \\
\hline Treonina total & 1,190 & 1,190 \\
\hline
\end{tabular}


Para a confecção das rações, os ingredientes foram moídos em triturador tipo martelo; posteriormente, foi realizada a mistura dos ingredientes em misturador " $Y$ ", e peletização. Após peletização, as rações foram novamente trituradas para atender ao diâmetro da boca dos guppys.

Dos parâmetros físico-químicos da água: o oxigênio dissolvido, $\mathrm{pH}$ e temperatura da água foram mensurados todos os dias durante 0 período experimental, com o auxílio de pHmetro (HANNA®) e Oxímetro/termômetro (ICEL®). O teor de amônia dissolvido na água foi avaliado uma vez por semana utilizando um kit colorimétrico comercial.

Ao final do experimento, os animais permaneceram em jejum por 15 horas para esvaziamento do trato digestório e posteriormente foram pesados e medidos para a obtenção do peso e medidas mofométricas.

Foram avaliados: o peso final; ganho de peso $=($ peso final $)-($ peso inicial); conversão alimentar $=($ consumo de ração) $\div$ (ganho de peso); comprimento total final (medido do focinho ao final da nadadeira caudal); ganho em comprimento total; comprimento padrão (medido do focinho ao início da nadadeira caudal); ganho em comprimento padrão; altura final ( medida à frente do $1^{\circ}$ raio da nadadeira dorsal); largura final (medida à frente do $1^{\circ}$ raio da nadadeira dorsal); taxa de crescimento específico $=[(($ In peso final - In peso inicial) $\div$ tempo) x 100]; taxa de desenvolvimento específico $=[((\mathrm{In}$ comprimento total final - In comprimento total inicial) $\div$ tempo) x 100]; e fator de condição de Fulton $=$ [peso final / (comprimento final) $\left.{ }^{3}\right] \times 100$.

Os dados obtidos foram submetidos à análise de variância, e em caso de diferenças aplicou-se o teste de médias $t$ de Student $(p>0,05)$.

\section{RESULTADOS E DISCUSSÃO}

Os valores médios de oxigênio dissolvido, $\mathrm{pH}$, temperatura e teor de amônia foram, respectivamente, 5,24 \pm $0,51 \mathrm{mg} / \mathrm{L} ; 6,39 \pm 0,06 ; 27,6 \pm 1,17{ }^{\circ} \mathrm{C}$; $0,63 \pm 0,43$ ppm permanecendo dentro da faixa aceitável para 0 bom desempenho da espécie (Lima, 2003). Não foram observadas mortes de peixes nas unidades experimentais.

Os peixes alimentados com ração contendo enzimas exógenas apresentaram maior peso final $(0,205 \mathrm{~g})$ e ganho de peso $(0,617 \mathrm{~g})$; Não houve diferença $(p<0,05)$ em relação ao consumo de ração (tabela 2). Os guppys alimentados com dietas contendo enzimas se mostraram mais eficientes em converter 0 alimento ingerido em produção de tecido, visto que, a conversão alimentar apresentou o melhor índice para os peixes alimentados com dietas contendo enzimas.

\footnotetext{
Tabela 2 - Desempenho de guppys alimentados com ração contendo ou não enzimas exógenas.

\begin{tabular}{llllll}
\hline & $\begin{array}{l}\text { Peso } \\
\text { inicial (g) }\end{array}$ & $\begin{array}{l}\text { Peso } \\
\text { final }(\mathrm{g})\end{array}$ & $\begin{array}{l}\text { Ganho de } \\
\text { peso(g) }\end{array}$ & $\begin{array}{l}\text { Consumo } \\
\text { de ração(g) }\end{array}$ & $\begin{array}{l}\text { Conversão } \\
\text { Alimentar }\end{array}$ \\
\hline $\begin{array}{l}\text { Dieta controle } \\
0,019^{\mathrm{a}}\end{array}$ & $0,166^{\mathrm{b}}$ & $0,147^{\mathrm{b}}$ & $0,720^{\mathrm{b}}$ & $4,88^{\mathrm{b}}$ \\
$\begin{array}{l}\text { Dieta controle } \\
+ \text { enzimas }\end{array}$ & $0,018^{\mathrm{a}}$ & $0,205^{\mathrm{a}}$ & $0,187^{\mathrm{a}}$ & $0,617^{\mathrm{b}}$ & $3,31^{\mathrm{a}}$ \\
\hline CV\% & 9,28 & 5,61 & 6,54 & 10,76 & 15,04 \\
\hline
\end{tabular}

*Médias na mesma coluna seguidas de letras distintas diferem $(P<0,05)$ pelo teste $t$.
}

Em outros peixes onívoros, como a tilápia do nilo, a inclusão de enzimas exógenas na forma de complexo enzimático também possibilitou melhores índices de conversão alimentar (Signor et. al, 2010). Evidenciando que a inclusão de enzimas em doses adequadas promove maior disponibilidade de nutrientes que podem ser rapidamente absorvidos.

A fitase atua quebrando ligações de complexos naturais, o fitato. Visando baratear as rações, dietas comerciais para peixes onívoros contêm farelos de origem vegetal. Uma quantidade considerável do fósforo presente nestes ingredientes não está prontamente 
disponível, havendo a necessidade da inclusão de fitase com a finalidade de melhorar a absorção do fósforo, visto que, os peixes não produzem a enzima de forma endógena. A adição de fitase em dietas para juvenis de tambaqui favoreceu melhores índices de conversão alimentar e ganho de peso (Mendonça et al., 2012).

A inclusão de enzimas digestivas exógenas não influenciou $(p<0,05) \quad 0$ comprimento final, ganho em comprimento e largura final dos guppys; no entanto, os peixes alimentados com ração contendo enzimas apresentaram maior altura final do que os animais cuja dieta não recebeu suplementação (tabela 3).

A altura do corpo dos guppys pode indicar um fator importante de desenvolvimento, visto que, estes peixes são popularmente conhecidos também como "barrigudinhos" devido a característica de ventre abaulado presente nas fêmeas.

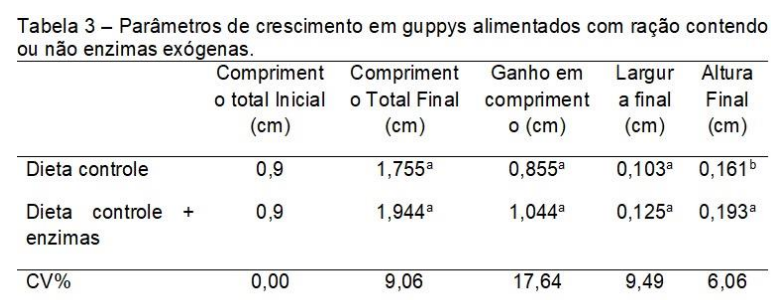

${ }^{\star}$ Médias na mesma coluna seguidas de letras distintas diferem $(P<0,05)$ pelo teste $t$.

Para o peixe ornamental kiguio (Carassius auratus), a suplementação das rações com complexo enzimático (amilase, protease, celulase, lipase, $\beta$ glucanase e fitase), não foi eficiente em influenciar diferenças significativas para parâmetros de desempenho, como o comprimento total (Signor et al., 2013).

Os índices de taxa de crescimento específico e taxa de desenvolvimento específico foram influenciados positivamente $(p<0,05)$ pela inclusão de enzimas na dieta (tabela 4).

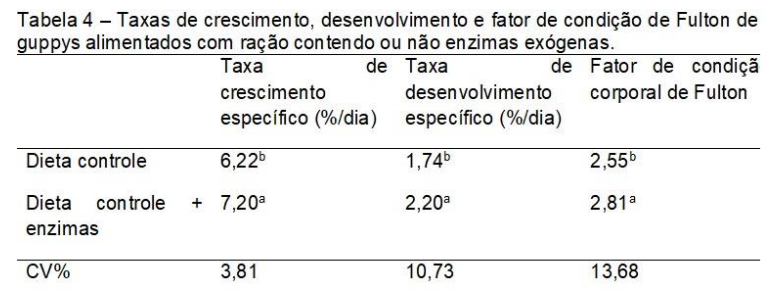

${ }^{\star}$ Médias na mesma coluna seguidas de letras distintas diferem $(P<0,05)$ pelo teste $t$.

Os maiores níveis para estes índices indicam que houve um ganho de peso e crescimento maiores em função do tempo do experimento nos guppys que receberam a dieta com adição de enzimas digestivas exógenas. Uma maior taxa de crescimento e desenvolvimento específicos pode indicar menor tempo de produção e, consequentemente retorno mais rápido do investimento.

O fator de condição corporal é utilizado para avaliar o bem-estar de peixes, é obtido através da relação entre peso e comprimento (Yamada et. al., 2008). O fator de condição de Fulton admite que a relação peso/comprimento é isométrica (igual a 3), por isso, para valores inferiores a 3 existe maior incremento em peso e, para valores superiores o maior incremento é devido ao comprimento (Rocha et al., 2005).

Os animais dos dois tratamentos apresentaram maior incremento em peso que comprimento, no entanto, os peixes guppys alimentados com rações contendo enzimas exógenas apresentaram valores mais próximos de 3 para o fator de condição corporal de Fulton $(\mathrm{P}<0,05)$, indicando melhores condições de desenvolvimento e bemestar.

\section{CONCLUSÃO}

Recomenda-se a suplementação de rações com as enzimas exógenas protease, alfa-amilase e fitase, visto que, sua inclusão influenciou de maneira positiva $o$ crescimento e desenvolvimento dos peixes ornamentais guppys. 
AGRADECIMENTOS

A CAPES, a empresa DSM e a empresa Aquavita.

\section{REFERÊNCIAS}

BOOCK, M. V.; MACHADO NETO, J. G. Estudos sobre a toxicidade aguda do oxicloreto de cobre para o peixe Poecilia reticulata. Boletim Instituto de Pesca, São Paulo, (31), v. 1, p. 29-35, 2005.

CAVALCANTI, L. P. D. G., PONTES, R. J. S., REGAZZI, A. C. F., JÚNIOR, P., FRUTUOSO, R. L., SOUSA, E. P., DANTAS FILHO, F. F. E LIMA, J. W. D. O. Competência de peixes como predadores de larvas de Aedes aegypti, em condições de laboratório. Revista de Saúde Pública, v. 4, n. 4, p. 638644. 2007.

LIMA, A. O. Aquicultura Ornamental: O potencial de mercado para algumas espécies de peixes ornamentais. Panorama da Aquicultura. v. 13, n. 78, p.28 29, 2003.

MENDONÇA, P.P.; COSTA, P.C.; POLESE, M.F.; VIDAL JR, M.V.; ANDRADE, D.R. Efeito da suplementação de fitase na alimentação de juvenis de tambaqui (Colossoma macropomum). Archivos de Zootecnia v. 61, n. 235, p. 437-448, 2012.

MUNAKATA, A; KOBAYASHI, M. Endocrine control of sexual behavior in teleost fish. General and Comparative Endocrinology, v. 165, p. 456-468, 2010.

ROCHA, M. A. DA, AZAMBUJA RIBEIRO, E. L. DE, MIZUBUTI, I. Y., DA SILVA, L. D. D. F., BOROSKY, J. C. \& RUBIN, K. C. P. Uso do fator de condição alométrico e de fulton na comparação de carpa (Cyprinus carpio), considerando os sexos e idade. Semina: Ciências Agrárias, v. 26, n. 3, 429-434. 2005.

SANTOS, E. L., LIRA, R. C., SOUZA, C. A., DE SOUZA SANTOS, I. V. V., DA
SILVA, F. C. B., ALBUQUERQUE, I. C. M. Desempenho de Betta splendens associados a diferentes frequências alimentares. Revista Científica de Produção Animal, v. 16, n. 1, p. 10-16, 2014.

Santos, E.S., Mota, S., Santos, A.B., \& Aquino, M.D. Cultivo do peixe ornamental molinésia (Poecilia sp.) em esgotos domésticos tratados: desempenho zootécnico e avaliação do bem-estar animal. Arquivo Brasileiro de Medicina Veterinária e Zootecnia, v. 67, n. 1, p. 255-264, 2015. SIGNOR, A. A.; BOSCOLO, W. R.; BITTENCOURT, F.; FEIDEN, A.; GONÇALVES, G. S.; FREITAS, J. M. A. Desempenho de juvenis de Tilápia-donilo alimentados com rações contendo complexo enzimático. Revista Brasileira de Zootecnia, v.39, n.5, p. 977-983, 2010.

SIGNOR, A.A.; LUCHESI, J.D.; COSTA, J.M.; FRIES, E.M.; ALTEVIR SIGNOR, A.; FEIDEN, A.; BOSCOLO, W.R. Complexo enzimático na dieta de alevinos de kinguio (Carassius auratus). Semina: Ciências Agrárias, Londrina, v. 34, n. 3, p. 1381-1388, 2013.

SOUZA, F. de; TOZZO, R. A. Poecilia reticulata $\quad$ Peters 1859 (Cyprinodontiformes, Poeciliidae) como possível bioindicador de ambientes degradados. Revista Meio Ambiente e Sustentabilidade, v. 3, n. 2, p. 162-175, 2013.

WEINSTEIN, M.; ZIMMER, B. Guppy Speed Dating: Male Mate Preference in Poecilia reticulata. Journal of Introductory Biology Investigations, v. 2, n. 5, 2015.

YAMADA, F. H., TAKEMOTO, R. M., \& PAVANELLI, G. C. Relação entre fator de condição relativo (Kn) e abundância de ectoparasitos de brânquias, em duas espécies de ciclídeos da bacia do rio Paraná, Brasil. Acta Scientiarum. 
Biological Sciences, v. 30, n. 2, p. 213217, 2008.

ZUANON, J. A. S., SALARO, A. L., \& FURUYA, W. M. Produção e nutrição de peixes ornamentais. Revista Brasileira de Zootecnia, v. 40, p. 165-174, 2011. 